menstrual cycle, convey concepts more dynamically than could ever be displayed on paper.

Video consultations demonstrate communication aspects powerfully. The introductory emphasis on the law, the client perspective and young people places contraception and sexual health within its psychosocial context. Links to referenced sites are well chosen and accessible. The interactive self-assessment is challenging and - dare I say fun, and I learned from some errors but I will not confess where!

I think e-SRH e-Learning is good preparation for the Practical Sessions of the FSRH Diploma, ${ }^{2}$ and with regular updating it will remain a valuable educational resource for us all in the future. Congratulations to all the team involved with this project.

Michael Tapley, MBBS, DFFP

Associate Specialist, Contraception and Sexual Health,ChoicesCentre@Town Central,

Stockport, UK.

E-mail: m.tapley@btopenworld.com

References

e-Learning for Healthcare. www.e-lfh.org.uk

[Accessed 4 April 2010].

Faculty of Sexual and Reproductive Healthcare

Diploma. www.fsrh.org [Accessed 4 April 2010].

\section{Query about Faculty updated UKMEC}

I would be grateful if the Faculty of Sexual and Reproductive Healthcare could explain why in the updated UK Medical Eligibility Criteria for Contraceptive Use (UKMEC 2009) $)^{1}$ the Category 4 for body mass index (BMI) $>40$, has been removed? As a raised BMI is so closely associated with increased risk of venous thromboembolism, this does not seem logical. Without the Category 4 status, I am concerned that increasing numbers of patients with a BMI $>35$ and indeed a $\mathrm{BMI}>40$, will start, or continue to take, the combined pill, without any robust guidance to support this as a dangerous practice.

I am, however, pleased to see the Category $3 / 4$ for multiple risk factors for cardiovascular disease is now clearly stated. I would, however, prefer the definition for 'older age' to be stated. I would interpret this as being aged 35 years or over, but the additional comments at the end of the section imply the definition is aged 40 or above.

I fully appreciate that UKMEC is a guidance document and not a list of rules as such, but if these are too loosely presented then they will not serve their purpose in ensuring safe prescribing practice.

\section{Deborah J Lee, MFFP, MRCGP}

Associate Specialist in Reproductive Health,

Lead Clinician CASH, Salisbury Department of

Sexual Health, Salisbury, UK

E-mail:Deborah.J.Lee@salisbury.nhs.uk

\section{Reference}

Faculty of Sexual and Reproductive Healthcare. UK Medical Eligibility Criteria for Contraceptive Use UKMEC 2009). 2009. http://www.fsrh.org/admin/ uploads/UKMEC2009.pdf [Accessed 10 March 2010].

\section{Reply}

In her letter, ${ }^{1}$ Dr Lee raises a pertinent question regarding the new UK Medical Eligibility Criteria for Contraceptive Use (UKMEC 2009)2 categories for body weight and combined hormonal contraception (CHC) use. The current Clinical Effectiveness Unit was not involved in updating UKMEC but we believe the body weight categories were made less restrictive to make them more consistent with the categories for other cardiovascular risk factors and $\mathrm{CHC}$.
The rationale for these changes is partly explained in an article by Trussell et al. ${ }^{3}$ Obesity is generally perceived to be an important risk factor in $\mathrm{CHC}$ users because of the high relative risk of venous thromboembolism (VTE). Trussell argues that, in terms of absolute or attributable risk, other cardiovascular risk factors are more strongly associated with VTE and mortality than obesity. For instance, the absolute risk of VTE in CHC users aged 45-49 years (UKMEC 2) is 175 per 100000 , which is greater than a VTE risk of 105 per 100000 associated with $\mathrm{CHC}$ use and body mass index $(\mathrm{BMI}) \geq 35$ (UKMEC 3 ). The risks in terms of deaths in $\mathrm{CHC}$ users are even lower, with an absolute risk of 3.3 deaths per 100000 in smokers aged $<35$ years (UKMEC 2) and a risk of 2.4 per 100000 in women with $\mathrm{BMI} \geq 35$ (UKMEC 3 ).

With regard to the UKMEC 2009 section on multiple risk factors for cardiovascular disease, the text is unchanged from UKMEC 2005. The additional comments do appear to imply that the UKMEC definition of 'older age' is aged 40 years or above. Risk factors such as age are a continuum and there is not necessarily an exact cut-off. As Dr Lee acknowledges, UKMEC is only a guidance document, and it would be entirely appropriate for clinicians to apply their own clinical judgement.

Louise Melvin, MRCOG, MFSRH

Director, FSRH Clinical Effectiveness Unit, and Consultant in Sexual and Reproductive Health, Sandyford, Glasgow, UK.

E-mail:louise.melvin@nhs.net

References

Lee DJ. Query about updated UKMEC (Letter). J Fam Plann Reprod Health Care 2010; 36: 181

2 Faculty of Sexual and Reproductive Healthcare. UK Medical Eligibility Criteria for Contraceptive Us (UKMEC 2009). 2009. http://www.fsrh.org/admi / uploads/UKMEC2009.pdf [Accessed 10 March 2010].

3 Trussell J, Guthrie K, Schwarz EB. Much ado about little: obesity, combined hormonal contraceptive use and venous thrombosis. Contraception 2008; 77 : 143-146.

\section{Implanon ${ }^{\circledR}$ failure in patients on antiretroviral medication: the importance of disclosure}

We would like to draw other practitioners attention to a problem we have observed recently in our clinic, namely Implanon ${ }^{\circledR}$ failure in two women on antiretroviral (ARV) medication who failed to mention Implanon use to their HIV physicians. These women highlight the need for disclosure of HIV diagnosis to physicians offering contraceptive choices and Implanon use to the HIV physicians.

A 33-year-old woman, para 3, attended in May 2007, requesting termination of pregnancy. She had an Implanon since July 2004 and was amenorrhoeic until February 2007. She was commenced on Sustiva ${ }^{\circledR}$ (efavirenz $600 \mathrm{mg}$ tab) and Truvada ${ }^{\circledR}$ (emtricitabine $200 \mathrm{mg}$ and tenofovir disoproxil $245 \mathrm{mg}$ ) in January 2007 as her HIV viral load was rising. She was not asked and did not volunteer Implanon use. Concerns for the adverse effect of the ARVs on the fetus had prompted the termination request. After a norma dating ultrasound scan her decision to terminate became ambivalent. She became committed to the pregnancy after a normal 15-week scan an delivered a male baby weighing $3520 \mathrm{~g}$ at term.

A 35-year-old woman, para 1, conceived with an Implanon when commenced on efavirenz and lopinavir. She did not mention Implanon use to the HIV physician, and the contraceptive clinic had no record of her HIV status. She did not appreciate that Implanon was a drug that might interact with ARVs. She had amenorrhoea on the Implanon and did not realise she was pregnant until 19 weeks. After counselling she opted for a mid-trimester termination.

The concentration of contraceptive hormones may change by concomitant drug use and vice versa. It is good practice to enquire about current and previous drug use (specifically liver enzyme-inducers) when offering hormonal contraceptives ${ }^{1}$ Women should be advised that some drugs might reduce hormonal contraceptive effectiveness. With the exception of the progesterone-only injectable or the levonorgestrel intrauterine system, the contraceptive efficacy of hormonal methods is reduced by liver enzyme inducers. ${ }^{1}$

Some ARVs, such as protease inhibitors (amprenavir, atazanavir, nelfinavir, lopinavir, saquinavir, ritonavir) and non-nucleoside reverse transcriptase inhibitors (efavirenz, nevarapine), are metabolised by the CYP3A4 liver enzyme system and can affect liver enzymes. ${ }^{1}$

Each Implanon contains $68 \mathrm{mg}$ etonogestrel (ENG). The subdermal delivery method makes it $100 \%$ bioavailable. Serum ENG concentrations increase rapidly within 8 hours of insertion and peak after 4 days. $^{2}$ The release rate is $60-70$ $\mu \mathrm{g} /$ day in weeks 5-6 post-insertion, and decreases to $35-45 \mu \mathrm{g} /$ day at the end of the first year, to 30-40 $\mathrm{ug} / \mathrm{day}$ at the end of the second year, and then falls to $25-30 \mu \mathrm{g} /$ day at the end of the third year. ${ }^{2,3}$ These low concentrations are sufficient to inhibit ovulation for 3 years ${ }^{3}$

The advice for using the progesterone-only implant for women on long-term liver enzymeinducing drugs is to continue using it together with additional contraceptive protection (such as condoms) and for 4 weeks after the drugs are stopped. ${ }^{1}$

These cases highlight the unforeseen consequences of non-disclosure of HIV for both patients and physicians. One of the dilemmas facing physicians is whether to disclose the HIV diagnosis to general practitioners (GPs). Arguments have been advanced for specialists breaching confidentiality and notifying the GP against patients' wishes in the interest of normal medical practice, the patients' and health personnel best interests, and the interests of society in general. Gillon 4 examines each argument and concludes that none is sufficient to justify violating physician patient confidentiality in most cases.

Early contraceptive failure of Implanon in a woman on antiretroviral medication has been described ${ }^{5}$ The patient in the case report had an ectopic pregnancy.

The great majority of HIV-positive women are of reproductive age. Contraceptive options must take into account the risk of an unintended pregnancy, vertical transmission, and horizontal transmission for a non-infected partner. To achieve all these goals, a combined contraceptive (barrier method plus another method) is the 'gold standard'. Some practitioners will argue that the 'Double DUTCH' advice should be given to all patients and not just HIV-positive women.

Nisha Lakhi, MD

Medical Student, Department of Obstetrics and Gynaecology, Brooklyn Hospital Center, Brooklyn, New York, NY, USA.

E-mail:nlakhi@yahoo.com

Abha Govind, MFSRH, FRCOG

Consultant, Department of Obstetrics and Gynaecology, North Middlesex University Hospital, Edmonton, London, UK. E-mail: Abha.Govind@nmh.nhs.uk

1 Faculty of Family Planning and Reproductive Health (April 2005). Drug interactions with hormance Cormonal 31: 139-151. Bennink HJ. The pharmacokinetics and pharmacodynamics of Implanon, a single-rod etonogestrel contraceptive implant. Eur J Contracept Reprod Health Care 2000; 5(Suppl. 2): 12-20. Reprod Health Care 2000; 5(Suppl. 2): 12-20.
Croxatto HB, Mäkäräinen L. The pharmacodynamics Croxatto HB, Makaarainen $L$. The pharmacodynamics Contraception 1998; 58(6 Suppl.): 91 S-97S. 